\title{
Multiplier Effect of the Role of Government Policy with Implementation of Corporate Social Responsibility in Order to Improve Performance and Competitiveness of UMKM in the Province of Bali
}

\author{
Gede Adi Yuniarta, Wayan Cipta, and I Putu Gede Diatmika
}

Faculty of Economics, Universitas Pendidikan Ganesha, Singaraja, Bali

\section{Abstract}

The Indonesian economy currently relies on Micro-, Small-, and Medium Enterprises (MSMEs). The important role of MSMEs is shown by their large numbers and moving in various business sectors and touching the interests of the community, being the business sector with the greatest contribution to national development, and creating considerable employment opportunities for domestic workers. The seriousness of the

Corresponding Author: Gede Adi Yuniarta gdadi_ak@yahoo.co.id

Received: 29 January 2019 Accepted: 27 February 2019 Published: 24 March 2019

Publishing services provided by Knowledge E

(c) Gede Adi Yuniarta et al. This article is distributed under the terms of the Creative Commons Attribution License, which permits unrestricted use and redistribution provided that the original author and source are credited.

Selection and Peer-review under the responsibility of the $3 \mathrm{rd}$ ICEEBA Conference Committee. government's role in improving the performance and competitiveness of MSMEs is needed, including making innovative efforts to take advantage of various opportunities including the assistance of the private sector. The implementation of Corporate Social Responsibility (CSR) can be seen as an alternative form of government intervention in terms of policy, so that the synergy of the private sector in implementing CSR with the MSMEs is expected to stimulate improvement in the performance and competitiveness of MSMEs. This study aims to prove the multiplier effect of the role of government policy with the implementation of CSR in order to improve the performance and competitiveness of MSMEs. The research sample was determined by the proportionate cluster random sampling of 67 MSMEs spread across Bali. Data analysis was carried out quantitatively using Partial Least Square Path Modeling. The results of the study prove that the role of government policy with the implementation of CSR concurrently influences the 5 performance variables and 6 variables of competitiveness of MSMEs. This proves that the role of government policy with the implementation of CSR has been proven to provide a multiplier effect on improving the performance and competitiveness of MSMEs.

Keywords: multiplier effect, role of government, implementation of CSR, performance, competitiveness, MSMEs

\section{Introduction}

The Indonesian economy currently relies on micro, small and medium enterprises (MSMEs). The important role of MSMEs as business subject is shown through the 
interests of the community. In addition to be a business sector that contributes the most to national development, MSMEs also create considerable employment opportunities for domestic workers, so their role is very important in helping the government's efforts to reduce unemployment. From the juridical aspect, the existence of MSMEs has been regulated legally through Law Number 20 of 2008 concerning Micro, Small and Medium Enterprises. The central government policy tool can be used as a foundation for a sustainable facilitation process.

During the period of 2008 to 2015, the number of MSMEs increased by $6,486,109$ units or $11.20 \%$. During this period, the number of employment absorption by MSMEs increased by $20,119,804$ people or $17.62 \%$. During the same period, the total GDP of MSMEs increased by Rp.4,328,355.2 billion or 50.62\%. (Ministry of Cooperatives and Small and Medium Enterprises of the Republic of Indonesia, 2015 Report). The government's policy to develop micro, small and medium enterprises (MSMEs), although it is continuously improved from year to year, it is not yet fully conducive. This can be seen, among others, the occurrence of unfair competition between small entrepreneurs and big entrepreneurs.

Similarly, the role of MSMEs in Bali Province, although well known for the tourism sector, only a few people work directly in that sector. Balinese people depend more on the MSME sector for their lives. Some of the dominant MSME sectors in Bali include: trade, handicraft, agriculture and tourism supporting industries. The seriousness of the government's role in improving the performance and competitiveness of MSMEs is needed, including making innovative efforts to take advantage of various opportunities including the assistance of the private sector (Scott, 2008). The implementation of Corporate Social Responsibility (CSR) can be seen as an alternative form of government intervention in terms of policy so that the synergy of the private sector in implementing CSR with the UMKM is expected to stimulate an increase in MSME performance and competitiveness (Grant, 2001)

This research attempts to prove a new theory constructed from the results of previous research by combining CSR implementation and prioritizing the role of government in relation to policies including CSR policies, business performance and competitiveness. The framework of thinking constructs several effects (multiplier effects) including: (1) The influence of the role of the government in improving the performance of MSMEs, (2) The influence of the government's role in improving the competitiveness of MSMEs, (3) The influence of government policies in the implementation of CSR in improving the performance of MSMEs, (4) The influence of government policies in implementing CSR in improving the competitiveness of MSMEs. 


\section{Research Methods}

This study examines the various roles of the government in an effort to improve the performance and competitiveness of MSMEs, including the role of the government in the policy of directing the implementation of CSR to support the improvement of MSME performance and competitiveness. There are five variables in this study which include 2 independent variables and 2 dependent variables. The independent variables consist of: (1) government policies related to MSMEs, (2) specific policies related to CSR Implementation. While the dependent variables include: (1) performance of MSMEs, and (2) competitiveness of MSMEs. Performance of MSMEs is proxied in 5 variables and the competitiveness of MSMEs is proxied in 6 variables. The population in this study were all MSMEs in Bali Province who directly accepted CSR implementation. The research sample was determined by the proportionate cluster random sampling of 67 MSMEs spread across Bali. The development of interview techniques guided by questionnaire guidelines is an attempt of this research to obtain reliable data as perceptual data which is expressed based on the honest attitude of respondent and the carefulness of field officers to obtain useful answers in accordance to the meaning contained in the researcher's questions (Fornell, 1982). Data analysis was carried out quantitatively using Partial Least Square Path Modeling.

\section{Results and Discussions}

The study determined the research sample based on the proportion of the number of MSME entrepreneurs proportionally based on the size of the population of MSME entrepreneurs scattered in Bali Province. Wayne W. Chin (1998) and Christian M. Rohing, (2013) recommend research samples can be taken between 30 to 100 respondents, considered to have been able to describe the characteristics of sample data, samples can be improved based on re-sampling methodology or bootstrapping techniques to get reliable information.

The research uses SPSS software as an initial step to evaluate the character of the respondent's data including assessment of the quality of the data generated from the research, which is about the feasibility of question items to be upgraded to valuable information in statistical tests. First, statistical tests using Explanatory Factor Analysis (EFA) analysis include dimensions of perception research-based data mapping, the feasibility of testing data questions that are expressed as indicators with choices 1 to 5 on a Likert scale. 
Statistical test to determine the initial condition of the perception data is done by looking at KMO (Kaiser-Meyer-Olkin) score and image correlation. The KMO score is recommended not smaller than 0.70 , while the image correlation per indicator is stated at the lowest limit is 0.50 . Characteristics of the respondents in this study include gender variables, entrepreneur education, type of business, level of production and age of respondents. For sex, it is stated 1 for men and 2 for women. While education, stated 1 for elementary school, 2 for junior high school, 3 for senior high school, 4 for diploma and 5 for undergraduate. The type of business is 1 for furniture and 2 for carving. Characteristics of respondents based on gender, showed that respondents selected as much as $85 \%$ were male and as many as $15 \%$ were female. Based on education level, as much as $55 \%$ of senior high school graduates, $25 \%$ of junior high school graduates, $5 \%$ of elementary school graduates, $10 \%$ are diplomas, and only $5 \%$ of graduate degrees.

\subsection{The role of the government in the performance of MSMEs}

The role of government policy (X1) turned out to have a positive and significant impact on the performance of MSMEs (Y1), based on a 5\% error rate, so that the role of government policy on the performance of MSMEs can be continued to the level of recommendations of this study. Business performance can be improved through government policies. Government policy predictions of 1.23401 were still higher than the sample average value of 1,124 indicating that the perception of MSME entrepreneurs could still change and increase based on perceptions obtained from predictions. This study proves that government policies can improve the performance of MSMEs.

\subsection{Government policy on the competitiveness of MSMEs}

The role of government policy (X1) turned out to have a positive and significant impact on the competitiveness of MSMEs (Y2), based on a $5 \%$ error rate, so that the role of government policy on the competitiveness of MSMEs can be continued to the level of recommendations of this study. The competitiveness of MSMEs can be increased through government policies. Government policy prediction of 1,321 was still higher than the sample average value of 1,209 indicating that the perception of MSME entrepreneurs could still change and increase based on perceptions obtained from predictions. This study proves that government policies can improve the competitiveness of MSMEs. 


\subsection{Government policy in implementing CSR in improving the performance of MSMEs}

The implementation of CSR by the private sector must be directed to beneficial activities, one of which is in fostering MSMEs in order to improve the performance of MSMEs. Improvement of the performance of MSMEs that are fostering by the private sector indirectly leads to an increase in community welfare (Barney, 1998). Based on the error rate of $5 \%$, obtained $t$-value of 5.472 which was still greater than the table $t=1.654$. Thus it can be stated that government policies in the implementation of CSR have a positive and significant effect on business performance. The results of statistical tests $t$ become a research guideline to state that government policies in implementing CSR are very strategic and relevant to be maintained in the future in order to improve the performance of MSMEs. The prediction of the influence of government policy in the implementation of CSR on the performance of MSMEs is 2.4791 which shows that the predicted value is still higher than the sample average of 2.2712 . Thus, it can be stated that government policies in the implementation of CSR could still change and increase based on perceptions obtained from predictions.

\subsection{Government policy in implementing CSR in improving the performance of MSMEs}

Based on the error rate of $5 \%$, which is where the value of $t=3.277$ was still greater than the $t$-table of 1,672 . Thus it can be stated that government policies in the implementation of CSR have a positive and significant effect on the competitiveness of MSMEs. The results of statistical tests $t$ become a research guideline to state that government policies in implementing CSR are very strategic and relevant to be maintained in the future in order to improve the competitiveness of MSMEs. Prediction of the influence of government policy in the implementation of CSR on the performance of MSMEs is 2,991 which shows that the predicted value is still higher than the sample average of 1,839. Thus, it can be stated that government policies in the implementation of CSR can still change and increase based on perceptions obtained from predictions.

\subsection{Research findings}

Based on the analysis of the results of data analysis, this study gets government policy with networking sub-constructs as a trigger in improving business performance. Government policy is also a supporter in improving the competitiveness of MSMEs. It turns out 
that government policies have a direct impact on business competitiveness and business performance. This study also found that in implementing CSR, the private sector must follow the policies set by the government, especially in fostering MSMEs. Government policy in implementing CSR can actually support efforts to improve MSME performance. Government policy in implementing CSR can support efforts to improve the competitiveness of MSMEs. Thus, this study found the need for the involvement of all components in improving the performance and competitiveness of MSMEs. Based on the results of the study, it is evident that a multiplier effect occurs due to government policies in order to improve the performance and competitiveness of MSMEs.

\subsection{Research limitations}

This study utilizes primary data based on perceptual research, so that the results of this study cannot be mapped as a pattern of business behavior as formulated in this research model to predict behavior patterns in the coming year. So that if the prediction of a number of constructs mapped when this research is carried out does not necessarily be used as a reference to determine the behavior patterns of entrepreneurs in the coming years. This is due to the dynamics of the time, where in the coming year there can be changes in government policy, direction of market competition and the entry of new entrepreneurs that bring along specific behaviors that require further research, to ensure the behavior of entrepreneur and changes that may occur over the intervention of a number of new variables that do not may be considered constant.

\section{Conclusion}

Based on the results of the research and analysis that has been done, it can be concluded that there is a multiplier effect due to government policies in order to increase the 5 performance variables and 6 variables of competitiveness of MSMEs. This is shown by the evidence: (1) the role of government has a significant influence in improving the performance of MSMEs, (2) the role of government has a significant effect on improving the competitiveness of MSMEs, (3) government policies in implementing CSR have a significant effect on improving the performance of MSMEs, (4) the government policies in the implementation of CSR has a significant effect on improving the competitiveness of MSMEs. 


\section{References}

[1] Afthanorhan, W. M. (2013). A comparison of partial Least Square Structural Equation Modeling (PLS-SEM) and covariance based structural equation. International Journal of Engineering Science and Innovative Technology, vol. 2, no. 5, pp. 198-205.

[2] Barney, J. B. and Wright, P. M. (1998). On Becoming a Strategic Partner: The Role of Human Resource in Gaining Competitive Advantage. Human Resources Management.

[3] Chin, W. W. (1998). The Partial Least Squares approach to structural equation modeling, in G. A. Marcoulides (ed.) Modern Methods for Business Research. London: Lawrence Erlbaum Associates.

[4] Ringle, C. M., Gotz, O., Wetzels, M., et al. (2013). On the use of Formative Measurement Specifications in Structural Equation Modeling: A Monte Carlo Simulation Study to Compare Covariance-Based and Partial Least Squares Model Estimation Methodologies. Hamburg Univ.

[5] Amir, E. and Imran, A. (2013). The effect of training on employee performance. European Journal of Business and Management, vol. 5, no. 4.

[6] Fornell, C. and Bookstein, F. L. (1982). Two structural equation models: LISREL and PLS applied to consumer exit-voice theory. Journal of Marketing Research, vol. 19, pp. 440-452.

[7] Grant, R. M. (2001). The Resource-Based Theory of Competitive Advantage: Implications for Strategy Formulation.

[8] Wiggins, R. R. (1997). Sustaining Competitive Advantage: Temporal Dynamics and The Rarity of Persistent Superior Economic Performance. A.B. Freeman School of Business Tulane University.

[9] Newbert, S. L. (2008). Value, rareness, competitive advantage, and performance: A conceptual-level empirical investigation of the resource-based view of the firm. Strategic Management Journal, vol. 29, pp. 745-768.

[10] Chin, W. W. (1998). A Partial Least Squares latent variable modeling approach for measuring interaction effects: Results from a Monte Carlo simulation study and voice mail emotion/adoption study. Journal of Marketing Research. 